\title{
Apontamentos sobre a formação do dispositivo do olhar no cinema
}

\section{Ana Maria Acker}

Doutora; Universidade Luterana do Brasil, Canoas, RS, Brasil

ana_acker@yahoo.com.br

\begin{abstract}
Resumo
$\mathrm{O}$ artigo traz alguns apontamentos sobre o dispositivo na formação do olhar do espectador no cinema e problematiza modos de ver e fruir as imagens em movimento. $\mathrm{O}$ dispositivo do olhar é pensado como o comportamento visual organizado na narrativa e as estratégias deste para afetar a forma de ver do público, os respectivos discursos em intentar o apelo sensível. Autores como Friedrich Kittler, Hans Ulrich Gumbrecht, Jonathan Crary, Marilena Chauí, Michel Foucault e Laurent Mannoni serviram de base para a reflexão. A discussão começa com aspectos teóricos em torno do conceito e se estende para três processos de formação do olhar ao longo do tempo por meio de alguns instrumentos visuais anteriores ao cinematógrafo. Tais objetos deixaram rastros no modo como a visão se compõe diante de telas e nas subjetividades derivadas da relação humana com esses artefatos.
\end{abstract}

\section{Palavras-chave}

Dispositivo. Olhar. Cinema. Tecnologia. Imagem. Comunicação.

\section{Introdução}

As possibilidades de como o olhar se organiza dentro de um filme mobilizam teóricos e críticos desde os primeiros escritos sobre cinema. A simples menção à palavra dispositivo coloca uma problemática com a qual não é simples lidar, pois sempre que se recorre a ela surgem os questionamentos sobre quais linhas teóricas guiam a discussão. Em síntese: não se menciona o dispositivo sem referência à tradição teórica que o cerca, e, mesmo quando não é citado literalmente, o conceito está em qualquer texto que se proponha a analisar a relação humana com imagens. 0 presente artigo realiza, portanto, alguns apontamentos sobre o dispositivo na formação do olhar no cinema e problematiza modos de ver e fruir as imagens em movimento. 
No recorte proposto, o dispositivo do olhar é pensado como o comportamento visual organizado na narrativa e as estratégias deste para afetar a forma de ver do público, os respectivos discursos em intentar o apelo sensível. Autores como Friedrich Kittler (2016), Hans Ulrich Gumbrecht (2014), Jonathan Crary (2012, 2013), Marilena Chauí (1988), Michel Foucault (1988, 1999) e Laurent Mannoni (2003) serviram de base para a reflexão. 0 argumento começa com aspectos teóricos em torno do conceito e se estende para três processos de formação do olhar ao longo do tempo por meio de alguns instrumentos visuais anteriores ao cinematógrafo. Tais objetos deixaram rastros no modo como a visão se compõe diante de telas e nos métodos de subjetivação derivados da relação humana com esses artefatos.

\section{A formação do olhar no cinema}

Os hábitos visuais do Ocidente são marcados pela perspectiva, que, conforme Friedrich Kittler (2016), é “[...] uma técnica de pintura que, desde mais ou menos 1420, representa todos os ângulos, linhas e proporções numa tela da mesma forma que eles se apresentam à retina." (KITTLER, 2016, p. 62). Consistia em um esforço de tornar a imagem o mais próximo possível tal qual a observamos no mundo, ou melhor, construía um modelo sobre como seria essa visão ideal. Ainda conforme Kittler (2016), a formação do olhar dos gregos se dá de maneira diferente:

Num mundo finito e encerrado em si, que os gregos veneravam na forma do cosmo como esfera ordenada, esse raio de visão conseguia alcançar sem qualquer esforço todas as coisas, inclusive as estrelas, que povoavam a superfície interna dessas esferas, pois a Antiguidade considerava infinita a velocidade da luz. Por sua vez, a perspectiva linear se baseia - no início, apenas implícita, mais tarde, explicitamente na suposição fundamental de um Universo infinito, ao qual corresponde um ponto de fuga infinitamente distante em cada pintura com perspectiva individual como modelo em miniatura desse Universo. (KITTLER, 2016, p. 63). 
Figura 1 - Escola de Atenas (de 1511), do italiano Rafael Sanzio

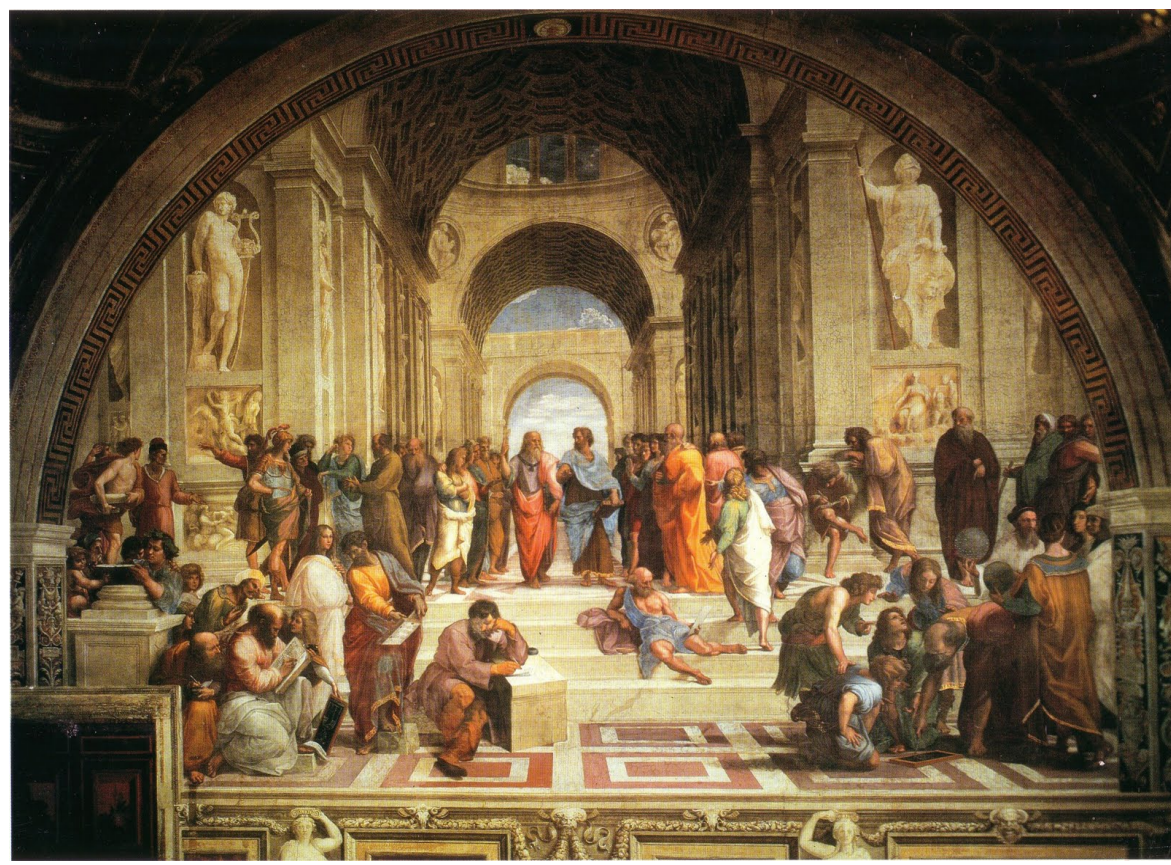

Fonte: Reprodução de $A$ Escola de Atenas do portal História das Artes (MARTINS, 2017).

Essa visão de mundo idealista, formatada na perspectiva da pintura (Figura 1), se transferiu ao maquinário cinematográfico, condicionando-nos a um olhar calcado nos pontos de fuga, composições harmoniosas (BAUDRY, 1983), como podemos identificar nessas imagens de filmes (Figuras 2 e 3) de Stanley Kubrick (1929 - 1999):

Figura 2 - As gêmeas do filme O Iluminado

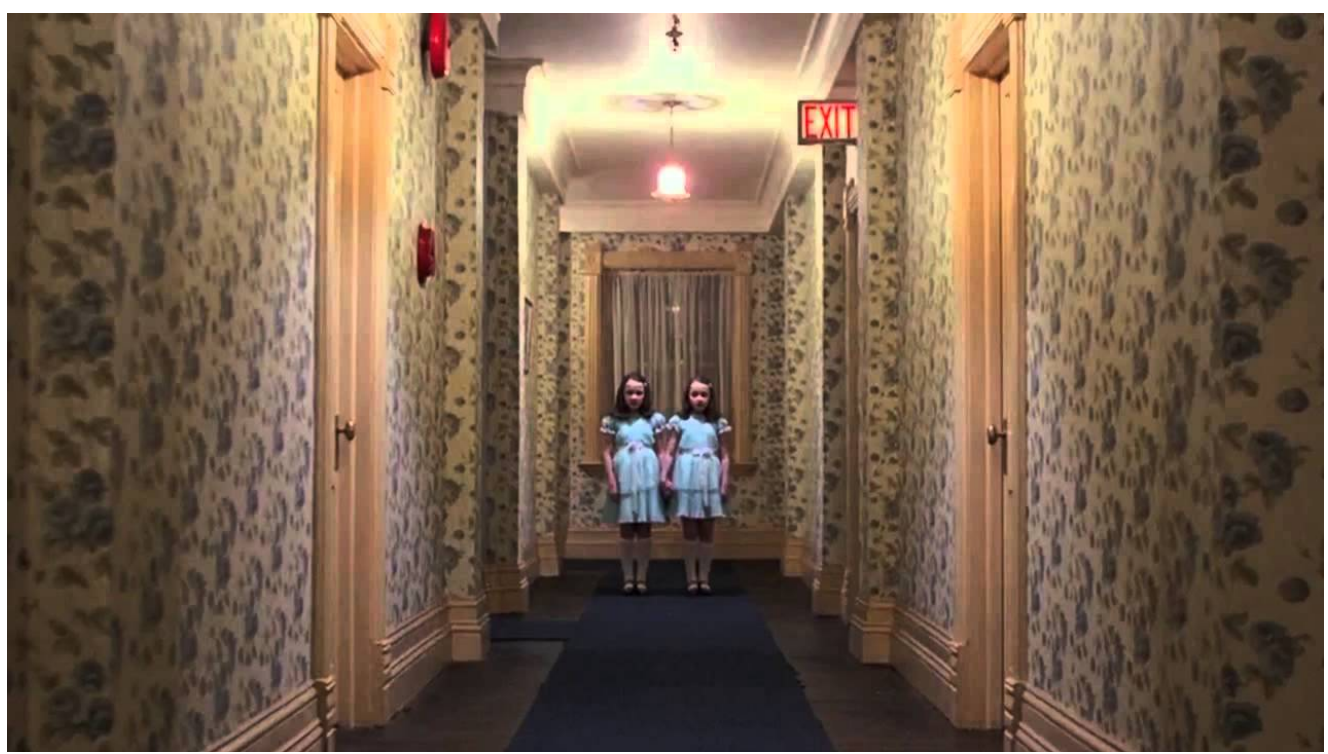

Fonte: Captura de imagem de O Iluminado (1980). 


\section{Figura 3 - Perspectiva em cena do filme Nascido para matar}

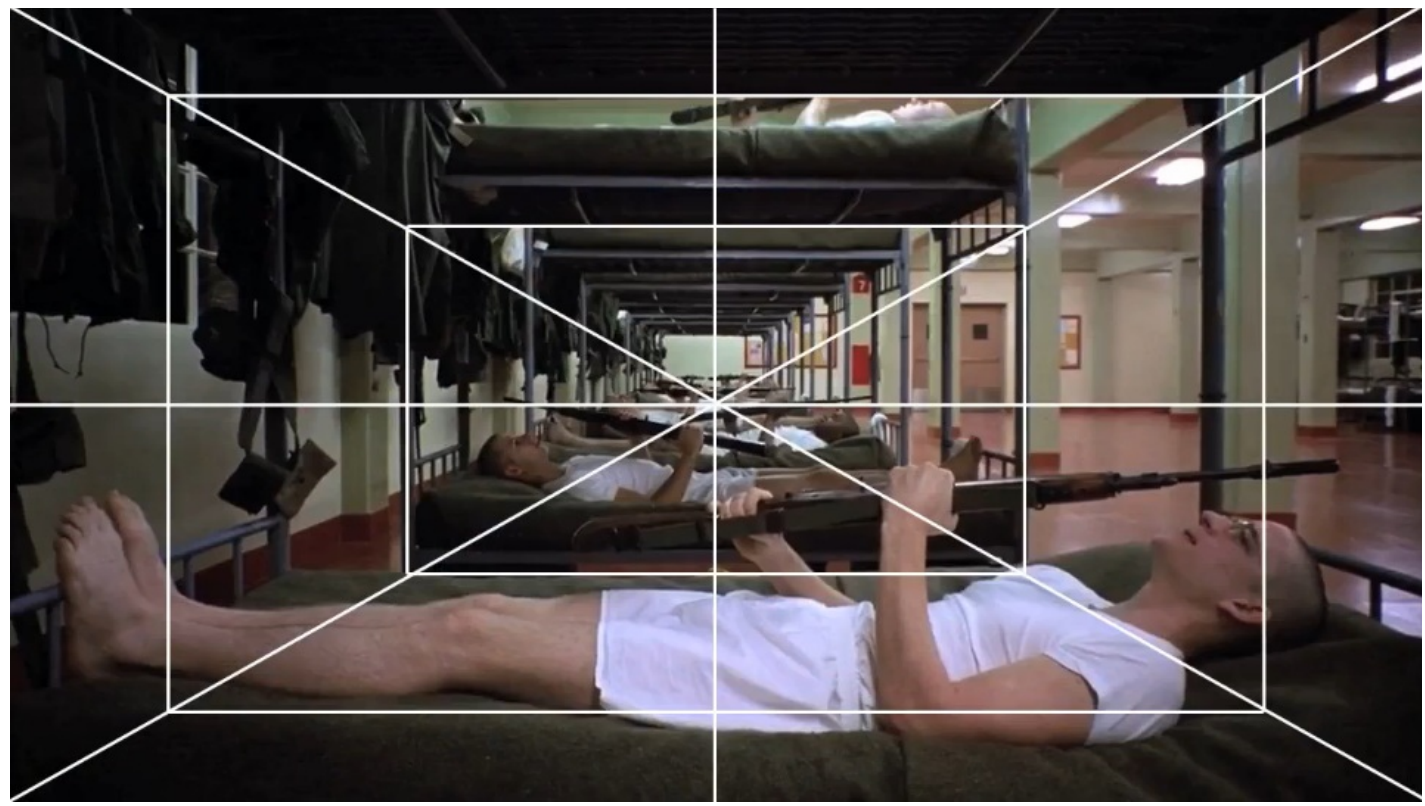

Fonte: Reprodução de Nascido para matar (1987).

Esses mecanismos não alcançariam eficácia, no entanto, sem a identificação do espectador com as imagens na tela. Já David Bordwell (2013) relativiza a influência da perspectiva renascentista, pois tal ideia ignora “[... o fato de que vários sistemas de perspectiva distintos foram elaborados dos anos 1300 aos anos 1600 e que eles frequentemente diferiam no norte e no sul da Europa." (BORDWELL, 2013, p. 229). Bordwell (2013) questiona qual sistema visual a câmera poderia ter produzido que fosse totalmente apartado da perspectiva em termos narrativos:

Uma coisa é dizer que o cinema ortodoxo reproduz apenas uma concepção de realidade; outra coisa é demonstrar que há outras realidades às quais o cinema, ou outros meios, poderia dar acesso. É verdade que há muitos esquemas pictóricos que não se baseiam na construção da perspectiva, como os retratos de animais de 'forma cindida' vistos na arte dos índios do noroeste da América. Mas como estes poderiam ter sido reproduzidos em imagens fotografadas em movimento? (BORDWELL, 2013, p. 229).

Outras referências são necessárias para uma contextualização de dispositivo que ultrapasse a dimensão da câmera, que leve em conta a constituição do olhar como uma rede de relações que passa por outros artefatos. Desta forma, Michel Foucault $(1988,1999)$ auxilia na percepção do termo. 
Giorgio Agamben (2005) observa que Foucault $(1988,1999)$ não formulou uma definição específica para dispositivo em seus escritos e o mais próximo de tal ação está em uma entrevista que o francês concedeu em 1977:

Aquilo que procuro individualizar com este nome é, antes de tudo, um conjunto absolutamente heterogêneo que implica discursos, instituições, estruturas arquitetônicas, decisões regulamentares, leis, medidas administrativas, enunciados científicos, proposições filosóficas, morais e filantrópicas, em resumo: tanto o dito como o não dito, eis os elementos do dispositivo. 0 dispositivo é a rede que se estabelece entre estes elementos [...]. (FOUCAULT, $1977^{1}$ apud AGAMBEN, 2005, p. 9).

Foucault (1988) diz que o dispositivo se trata de "[...] uma certa manipulação de relações de força" [...] [ele] - "está sempre inscrito num jogo de poder e, ao mesmo tempo, sempre ligado aos limites do saber, que derivam desse e, na mesma medida, condicionamno" FOUCAULT, 1977, apud AGAMBEN, 2005, p. 28). Entretanto, pensar esse campo de relações de forças não deve pressupor uma tensão de poderes apenas calcada na interdição, pois como observa Foucault (1988), nossa sociedade "foi mais inventiva do que qualquer outra em mecanismos de poder sutis e delicados" (FOUCAULT, 1988, p. 83). 0 poder só é tolerável, argumenta o filósofo, justamente porque mascara muitos de seus processos e se desenvolve em ambientes diversos: “[...] o poder não é uma instituição e nem uma estrutura, não é uma certa potência de que alguns sejam dotados: é o nome dado a uma situação estratégica complexa numa sociedade determinada" (FOUCAULT, 1988, p. 89). Ou seja, se o dispositivo é uma estrutura, rede de discursos onde se estabelecem relações de força, é oportuno atentar para as sutilezas dos jogos de poder que constituem os modos de ver a partir das telas técnicas.

Foucault (1988) observa que o poder, ou melhor, o biopoder, se reordena nos corpos, nas preocupações com a saúde, naquilo que fundamenta um cuidado de si. É nesses meandros da vida humana que o embate de forças se disfarça e por conta disso se estende com mais intensidade:

[...] as correlações de força múltiplas que se formam e atuam nos aparelhos de produção, nas famílias, grupos restritos e instituições, servem de suporte a amplos efeitos de clivagem que atravessam o conjunto do corpo social. Estes formam, então, uma linha de força geral que atravessa os afrontamentos locais e os liga entre si; evidentemente, em troca, procedem a redistribuições, alinhamentos, homogeneizações, arranjos de série, convergências desses afrontamentos locais. As grandes dominações são

\footnotetext{
${ }^{1}$ FOUCAULT, Michel. Le jeu de Michel Foucault. Entretien avec D. Colas et al. Bulletin Périodique du champ freudien, [s.l.], n. 10, p. 62-93, julliet 1977.
} 
efeitos hegemônicos continuamente sustentados pela intensidade de todos estes afrontamentos; [...] (FOUCAULT, 1988, p. 90).

A abordagem de Foucault (1988) nesse caso, foge da ideia de poder como resultado da relação entre dominadores e dominados: a questão se dá em diversos atravessamentos, o que complexifica a identificação das estratégias de dominação. Com base nas características da ideia de dispositivo do teórico, pode-se afirmar que a formação do modo de ver cinematográfico está relacionada ao conceito de dispositivo foucaultiano, conectada a essa rede de forças, poderes.

O cinema é, sobretudo, um dispositivo do olhar. 0 que já se sabe é que “[...] cerca de $60 \%$ de todas as informações que alcançam o cérebro sejam de origem visual, e que o cérebro utiliza uma proporção considerável da sua capacidade (cerca de 30\%) para processar essas informações." (ZIELINSKI, 2006, p. 106). Já Jonathan Crary (2012) salienta que as imagens sintetizadas (simuladores, ressonâncias magnéticas, realidade virtual) de alguma forma "estão deslocando a visão para um plano dissociado do observador humano" (CRARY, 2012, p. 11). A função do olho está sendo substituída por práticas em que essas visualidades não mantêm mais uma relação com um observador em um mundo "real", destaca o Crary (2012): “Cada vez mais a visualidade situar-se-á em um terreno cibernético e eletromagnético em que elementos abstratos, linguísticos e visuais coincidem, circulam, são consumidos e trocados em escala global." (CRARY, 2012, p. 12).

As transformações são profundas, só que outras, tão significativas quanto, ocorreram em diversos períodos da história. Entre esses momentos, Crary (2012) discorre sobre as mudanças no estatuto do olhar ocorridas no século XIX, quando as máquinas de reprodução e extensão visual tensionaram aquilo que era instituído pelas artes plásticas. Apesar disso, o autor não condiciona as alterações somente ao desenvolvimento técnico, pois para ele o observador do século de XIX, ou de outros períodos, “[...] somente o é como efeito de um sistema irredutivelmente heterogêneo de relações discursivas, sociais, tecnológicas e institucionais." (CRARY, 2012, p. 15, grifo do autor). Nessa citação, é possível perceber relações entre o pensamento de Crary (2012) e o conceito de dispositivo em Foucault (1984) A técnica por si só não modifica todo um regime de olhar, existem outras forças em curso e essas são fundamentais para o entendimento de como nos portamos diante de imagens ao longo da história.

Logo, a perspectiva renascentista mantém traços na gênese das imagens técnicas, no entanto não é o único modelo: diversos foram os instrumentos visuais que ao longo do tempo formaram, por meio de relações de poderes, o dispositivo do olhar no Ocidente. Os 
usos, os discursos, as forças que permearam essas mudanças muitas vezes não são explicitadas com clareza diante de uma ilusão marcada pela ideia de evolução técnica contínua. Por isso, as contribuições de Foucault (1988) e Crary (2012), auxiliam nesse entendimento de que foram variados os objetos e processos que levaram à relação com as visualidades.

\section{Instrumentos pré-cinema e modos de ver}

Alguns pontos a respeito das mudanças ocorridas na Modernidade nos ajudam a pensar o que transcorre na contemporaneidade. As transformações, que se intensificaram no século XIX, trouxeram desafios: as pessoas precisavam viver em cidades que cresciam rapidamente, se acostumar aos deslocamentos de trem, bem como aos fluxos de informação via telégrafo (CRARY, 2012). "A identidade discursiva do observador, como objeto de reflexão filosófica e de estudo empírico, passou por uma renovação igualmente drástica" (2012, p. 20). Crary complementa que "A modernidade [...] coincide com o colapso dos modelos clássicos de visão e seu espaço estável de representações." (CRARY, 2012, p. 32). Essa ruptura ocorreu principalmente em função dos aparelhos de visão que se desenvolveram a partir do período, contudo as transformações tiveram início muito antes.

As pesquisas científicas sobre o olho ajudaram a delinear a projeção de diversos instrumentos como o fenacistoscópio ${ }^{2}$, o estereoscópio ${ }^{3}$ e o zootrópio ${ }^{4}$ (CRARY, 2012). Houve um processo de sujeição do observador e tais impactos aconteceram antes da fotografia:

0 que tem início nas décadas de 1820 e 1830 é um reposicionamento do observador, fora das relações fixas de interior/exterior que eram pressupostas pela câmara escura e que vai em direção a um território não demarcado, no qual a distinção entre sensação interna e sinais externos torna-se definitivamente opaca. Se alguma vez houve uma "liberação" da visão no século XIX, é nesse momento que ela ocorre pela primeira vez. (CRARY, 2012, p. 32).

A visão se torna emancipada, suas estruturas e objetos já não são tão rígidos e Crary (2012) pondera que outros meios de recodificar e ordenar o olhar aparecem: "Trata-se de técnicas disciplinares que solicitaram uma concepção de experiência visual como algo instrumental, modificável e abstrato, e que jamais permitiram que um mundo real adquirisse solidez ou permanência." (CRARY, 2012, p. 32). Houve um rompimento com o

\footnotetext{
${ }^{2}$ Instrumento que cria uma ilusão óptica de movimento, baseada na persistência da imagem na retina (FENACISTOSCÓPIO, 2018).

${ }^{3}$ Instrumento óptico por meio do qual as imagens planas se nos afiguram em relevo (ESTEREOSCÓPIO, 2018).

${ }^{4}$ Aparelho composto por um cilindro com cortes verticais laterais, que, quando se gira, dá ao espectador a ilusão do movimento das imagens estáticas dispostas em tira em seu interior (ZOOTRÓPIO, 2018).
} 
modelo visual da câmara escura, que por muito tempo (em especial os séculos XVII e XVIII, afirma Crary (2012) fundamentou a relação perceptiva dos sujeitos com o mundo.

De objeto usado para diversão popular a algo para investigações científicas, a câmara escura não constituía apenas um instrumento técnico, mas social e cultural da época. Ela apresentava a possibilidade "[...] de separar o ato de ver e o corpo físico do observador, ou seja, descorporificar a visão. [...] a experiência física e sensorial do observador é suplantada pelas relações entre um aparato mecânico e um mundo previamente dado da verdade objetiva." (CRARY, 2012, p. 46). Nesse esquema de funcionamento, o corpo do sujeito acaba apartado da representação.

A separação entre sujeito e representação pode levar a uma interpretação equivocada da câmara escura, como se o aparelho e o observador fossem entidades distintas (CRARY, 2012). Esse objeto tem um perfil múltiplo: “[...] a câmara escura não pode ser reduzida nem a um objeto tecnológico nem a um objeto discursivo: ela é um complexo amálgama social cuja existência textual é inseparável de seus usos mecânicos" (CRARY, 2012, p. 37). Crary (2012) observa que a câmara isolou o sujeito no ato de fruição com as imagens e isso faz dela algo "inseparável de uma metafísica da interioridade" (CRARY, 2012, p. 45). Além disso, não há como inserir o indivíduo no processo de representação da câmara escura, pois ele está sempre separado dela.

Esse instrumento, todavia, era um dos vetores de uma problemática que ocorria em outras manifestações culturais e artísticas, entre elas a pintura. Ao discorrer sobre as obras de Caspar David Friedrich (1818a, 1818b) 1774 - 1840, Hans Ulrich Gumbrecht (2014) salienta que o artista realizou muitas pinturas com pessoas que observam o mundo (Figuras 5 e 6), algo que se tornou frequente em outras obras, especialmente a partir de 1815. Conforme Gumbrecht (2014), aquilo que Foucault (1999) identificou como a crise da representação, ou Niklas Luhmann (apud GUMBRECHT, 2014) denominou "observação de segunda ordem", se tornou uma discussão recorrente na sociedade do século XIX a partir do entendimento de que as pessoas viam as coisas e percebiam o entorno de modos diferenciados:

A emergência da observação de segunda ordem - exemplificada pelas figuras nos quadros de [Caspar] Friedrich - dá o tom para a discussão filosófica, ao colocar dois problemas. Contrariamente à natureza e aos modos do racionalista, o sujeito "cartesiano" (cogito ergo sum) herdado dos séculos XVII e XVIII, para quem a capacidade do intelecto se baseia apenas na consciência, o observador de segunda ordem redescobre como a sua relação com as coisas-do-mundo é determinada não só pelas funções conceptualizantes da consciência, mas implica também os sentidos. Resulta, então, a questão - que está ainda por ser respondida - sobre o 
caráter preciso da relação entre experiência e percepção (GUMBRECHT, 2014, p. 86).

Conforme Gumbrecht (2014), o segundo problema colocado por esse tipo de pintura seria a compreensão de que a interpretação do mundo depende da posição que o observador ocupa, ou seja, há uma multiplicidade de pontos de vista diante de um único fato ou ambiente:

Consequentemente - e isso se percebe de modo muito claro na nossa visão retrospectiva das primeiras décadas do século XIX -, surgiu algo como um horror vacui epistemológico: o medo (por mais rara que fosse a compreensão da origem ou da essência do fenômeno) de que, em face de um número potencialmente ilimitado de representações para cada objeto ou experiência, em última análise poderia não haver nenhum referente nenhum índice material no mundo (GUMBRECHT, 2014, p. 86).

Estava tomando forma a consciência da instabilidade da relação com as coisas, a fluidez, a perda de referências. Esses fenômenos se tornavam cada vez mais aparentes, tanto nas artes quanto nos instrumentos vulgares de entretenimento produtores de luzes e sombras. Se Gumbrecht (2014) cita um artista do século XIX para problematizar a fluidez do olhar; Foucault (1999) identifica em uma pormenorizada análise do quadro As meninas, de 1656, do espanhol Diego Velázquez. De acordo com Foucault (1999), a obra enigmática já desvela uma instabilidade do olhar, ou melhor, olhares que suscita:

\begin{abstract}
Nenhum olhar é estável, ou antes, no sulco neutro do olhar que traspassa a tela perpendicularmente, o sujeito e o objeto, o espectador e o modelo invertem seu papel ao infinito. E, na extremidade esquerda do quadro, a grande tela virada exerce aí sua segunda função: obstinadamente invisível, impede que seja alguma vez determinável ou definitivamente estabelecida a relação dos olhares. A fixidez opaca que ela faz reinar num lado torna para sempre instável o jogo das metamorfoses que, no centro, se estabelece entre o espectador e o modelo. Porque só vemos esse reverso, não sabemos quem somos nem o que fazemos. Somos vistos ou vemos? 0 pintor fixa atualmente um lugar que, de instante a instante, não cessa de mudar de conteúdo, de forma, de identidade. (FOUCAULT, 1999, p. 5).
\end{abstract}

Não é questão aqui retomar os debates em torno de As meninas (Figura 4), todavia podemos perceber que a obra interpela quem a vê, tensiona possíveis certezas diante do que foi pintado, da posição do artista na cena e do espectador diante da cena. 0 ato de contemplar se desdobra de diversas e intrigantes formas frente à tela do século XVII. Ainda conforme Foucault (1999) há "três funções olhantes na obra": dos modelos retratados (o rei Filipe IV e a rainha Maria Ana da Áustria), do espectador e do pintor no momento em que compõe a pintura (FOUCAULT, 1999, p. 17). Além disso, o homem ao fundo é o único que 
visualiza os soberanos frontalmente, direito negado aos observadores do quadro (Figura 4). Podemos, de certo modo, pensar em várias cenas dentro de uma mesma composição pictórica, e, relacionando a abordagem de Gumbrecht (2014) à observação de segunda ordem ao quadro de Velázquez (1656), temos aqui observador e observado de segunda ordem, pois o espectador igualmente é 'observado'.

Figura 4 - Foucault afirma que As meninas desestabiliza o olhar

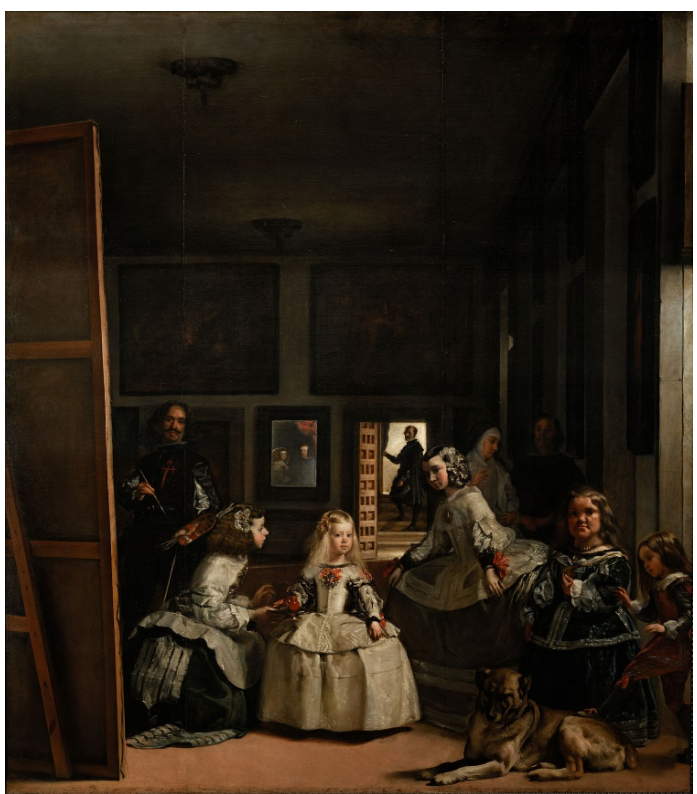

Fonte: Reprodução de As meninas de Velázquez (1656).

Figura 5 - Em Penhascos de giz em Rügen vemos pessoas que observam o mundo

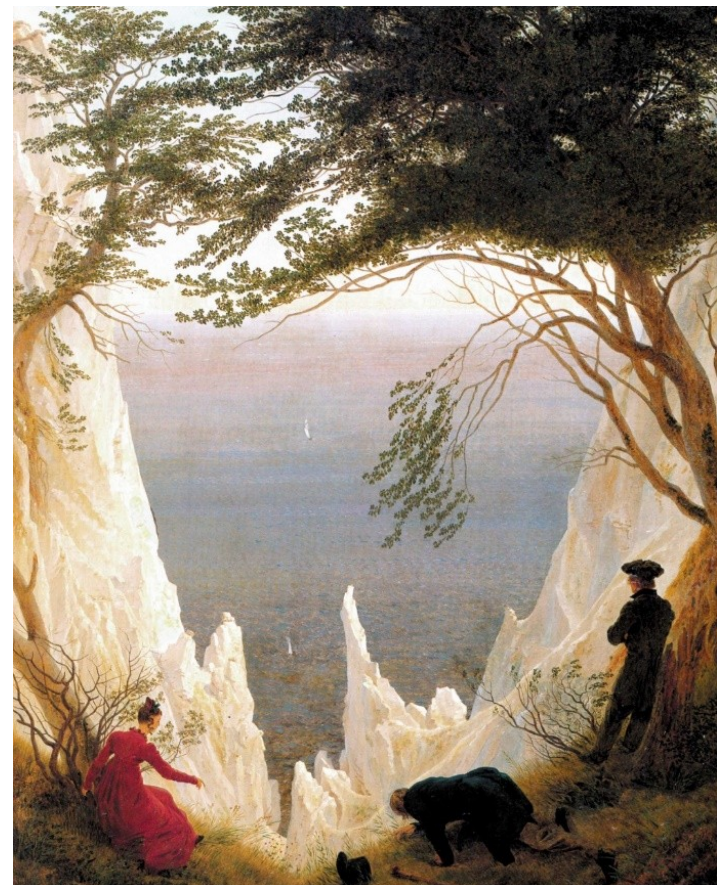

Fonte: Friedrich (1818b), reprodução da obra em Web Gallery of Art (2019). 
Observar alguém olhando é diverso de contemplar um indivíduo que olha ao mesmo tempo em que é vigiado por um processo não humano, característica que identificamos no cinema contemporâneo.

Figura 6 - Mulher diante da aurora (1818) evidencia a instabilidade do olhar

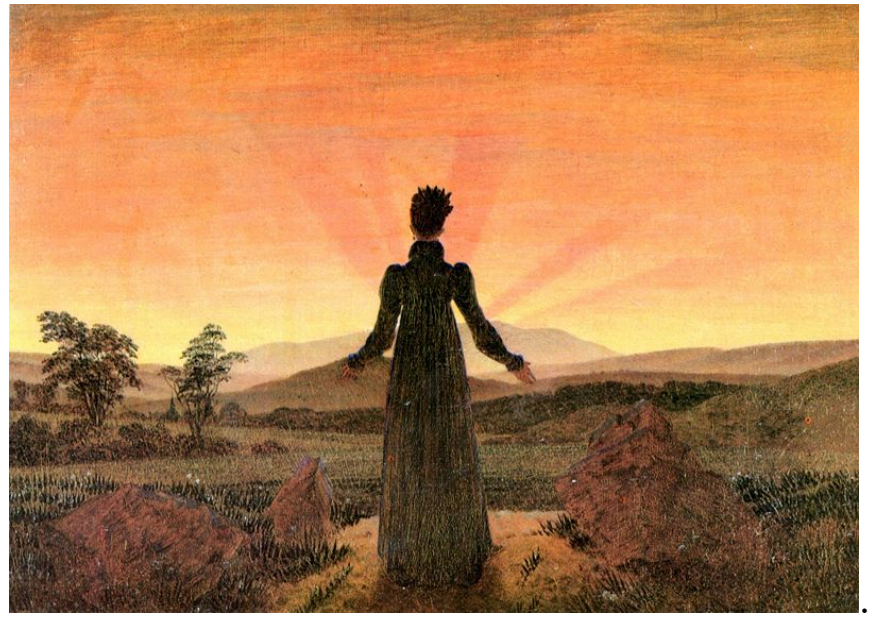

Fonte: Friedrich (1818a), reprodução da obra em Web Gallery of Art (2019).

Figura 7 - Imagem digital de Atividade Paranormal 4 remete ao quadro de Friedrich

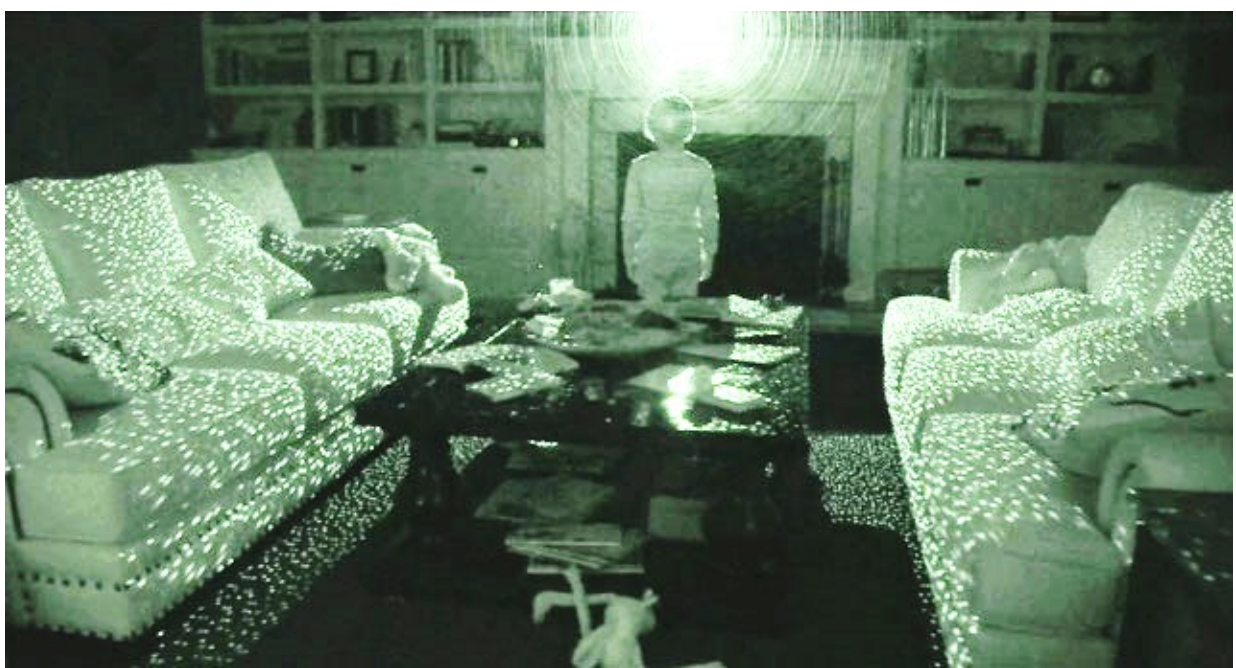

Fonte: Captura de imagem de Atividade Paranormal 4 (2012).

Se conforme Gumbrecht (2014), o observador de segunda ordem da pintura (Figuras 5 e 6) do novecentos evidenciava uma desestabilização do olhar e das concepções diante do mundo que se desenvolvia rapidamente; no cinema do século XXI o uso da câmera de vigilância e outros aparelhos móveis como mecanismos narrativos coloca os artefatos de protagonistas na ação e enfatiza ainda mais o olhar disperso e desmaterializado da contemporaneidade (Figura 7). A máquina vê alguém que observa e tal presença e colabora 
para a tensão de não se saber ao certo quem ou o que olha para os personagens no filme. 0 olhar é desmaterializado em aparelhos, e isso se intensificou a partir da câmara obscura, como se as imagens de síntese finalizassem um processo iniciado séculos atrás.

A crença nos objetos tecnológicos como vetores para ver melhor é algo característico da Modernidade. As transformações científicas em diversas áreas contrastam com a instabilidade visual do período, conforme afirma Marilena Chauí (1988):

Os textos modernos sobre a visão são curiosos. Esquadrinham o olho, o sentido da vista, as coisas visíveis com o intuito de separar em cada um deles o subjetivo (ou ilusório) e o objetivo (ou verdadeiro), decompondoos em qualidades e propriedades a serem reunidas pela síntese do pensamento. Porque referidos ao mundo como realidade em si - a Natureza como ens realissimum - e porque nosso corpo é uma coisa natural entre as demais coisas naturais, intriga-os que ele não tenha acesso a elas e, pior que isto, enganando-se sobre elas, introduza a desordem no real. A Natureza, objetivada nas representações da geometria, da álgebra e da mecânica, é forma, figura, massa, volume e movimento, propriedades reguladas pelo princípio da causalidade. Porém, sobre a superfície das coisas em si começam a depositar-se fantasmas e simulacros - cores, odores, sabores, texturas - e são justamente estes que nosso corpo percebe, tomando-os pela realidade. (CHAUÍ, 1988, p. 56).

0 ato de dar-se conta de que a cientificidade esbarrava nas nuances do visual, do perceptivo foi algo difuso. Embora esse entendimento tenha se potencializado na Modernidade, é antiga a tradição de manipulações e experimentos com o olhar. A câmara escura, por exemplo, tem uma origem longínqua. De acordo com Zielinski (2006), provavelmente foi Aristóteles, no contexto ocidental, quem primeiro apontou o caráter científico do fenômeno no século IV a.C.: "De modo elaborado, descreveu o fenômeno no caso de raios de luz passando através da folhagem, e empregou isso para estudar os eclipses solares" (ZIELINSKI, 2006, p. 108). Há relatos de descrições semelhantes na China, no século V a.C em textos do filósofo natural Mo Ti (ZIELINSKI, 2006).

Seres, coisas se moviam e isso era inédito para as pessoas que acompanhavam esse tipo de espetáculo. Só que não era apenas o realismo das imagens que atraía o público que começava a se formar para essas atrações. Assim como a câmara escura, os espelhos despertavam curiosidade, especialmente pelo aspecto misterioso (MANNONI, 2003). Ainda no século XVII, o jesuíta alemão Athanasius Kircher conseguiu "[...] unir duas técnicas de projeção, a câmara escura e os espelhos. Criou sistemas ópticos muito elaborados para espetáculos de imagens luminosas, mas ainda totalmente dependentes da luz solar." (MANNONI, 2003, p. 45). 
O século XVII foi fundamental para o desenvolvimento de aparelhos óticos cientificamente embasados que culminariam na invenção do cinema posteriormente, pois, como argumenta Mannoni (2003), foi durante os 1600 “[...] que se inventaram aparelhos de importância fundamental para a materialização futura do cinema, quando mecanismos científicos vieram substituir os velhos métodos naturais, forçosamente limitados." (MANNONI, 2003, p. 51).

Figura 8 - Referência à lanterna em texto de Giovanni da Fontana, de 1420

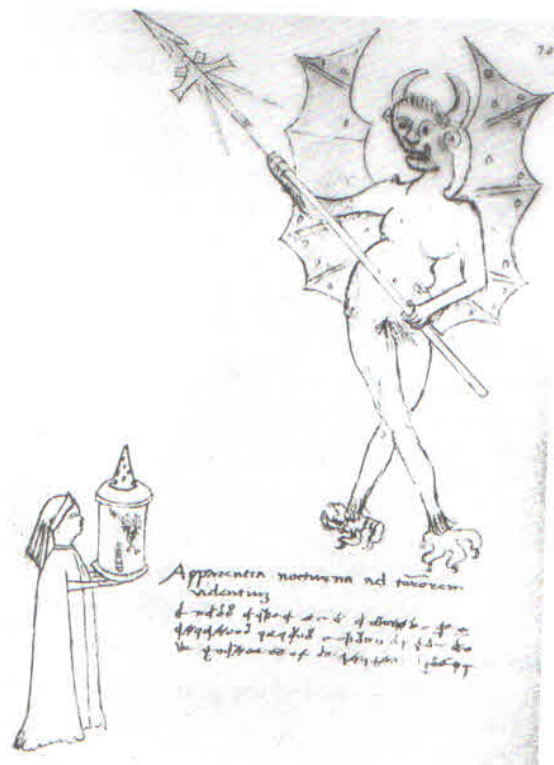

Fonte: Mannoni (2003, p. 56).

Entre esses instrumentos, um ainda mais antigo já encantava com imagens que giravam e seduziam: as lanternas vivas da Idade Média. Não formavam uma projeção propriamente dita, mas davam vida em cores a figuras interessantes (Figura 8) e, muitas vezes, assustadoras:

Uma tira de papel translúcido pintado com figuras grotescas ou diabólicas era colocada dentro de um cilindro de papel ou de chapa de ferro decorativamente perfurada. Na parte de cima do cilindro, colocava-se uma espécie de hélice de estanho, que girava em torno de um eixo, uma haste de ferro, onde se fixava o desenho translúcido. Uma vela ardia no centro da lanterna, e o calor por ela produzido fazia girar a hélice, movendo a tira de papel pintado. As figuras de cores vivas giravam assim em torno de seu coração luminoso e projetavam em torno de si vagos reflexos matizados. Se o cilindro fosse de metal vazado, as imagens pintadas dançavam nas paredes em volta. 0 efeito era limitado, mas tinha um certo encanto. (MANNONI, 2003, p. 53). 
Já a lanterna mágica surgiu posteriormente, sendo denominada assim por volta de 1668 (MANNONI, 2003). 0 objeto foi um dos mais duradouros na realização de espetáculos nesse período pré-cinema: "Ao longo do seu reinado, que se estende por três séculos, ela exibiu imagens artificiais, fixas e animadas a um público sempre maravilhado e exigente. Correu o mundo, a uma velocidade prodigiosa." (MANNONI, 2003, p. 57). A lanterna mudou pouco ao longo dos anos (do século XVII ao XIX), mantendo-se basicamente como uma caixa de madeira com uma parte cilíndrica que projeta sobre alguma superfície: "Diabruras, cenas grotescas, eróticas, escatológicas, religiosas, históricas, científicas, políticas, satíricas: todos os assuntos foram abordados." (MANNONI, 2003, p. 58). Kittler (2016) salienta qual era a principal inovação do instrumento:

\begin{abstract}
A história das mídias ópticas nos permite compreender isso com uma precisão maior: o aparelho técnico que apresenta a representação (no lugar do real) é a lanterna mágica. A imagem de algo (ou seja, sua representação) é introduzida em uma caixa negra e exposta à luz, que projeta uma representação dessa representação, uma imagem de sua imagem, sobre a parede. (KITTLER, 2016, p. 100, grifo do autor).
\end{abstract}

Kittler (2016) diz, ainda, que a lanterna produziu o desejo pela tecnologia cinematográfica e deu origem à ocupação de lanternista ambulante, pessoa que viajava por diversas cidades levando o instrumento para apresentações de imagens, como as de terras distantes. Nos escritos dessa época, era comum a confusão entre a lanterna mágica (Figura 8) e a caixa óptica: enquanto o primeiro permitia a projeção; no segundo a experiência era individual. $\mathrm{O}$ formato mais comum, segundo pesquisas de Mannoni (2003), é

[...] uma caixa no formato de pirâmide truncada, em cima da qual há uma outra caixa, retangular, contendo o material óptico e o espelho. A gravura, iluminada e deitada no fundo da caixa, é vista através de uma lente biconvexa [...] e de um espelho com inclinação de 45 graus [...]. (MANNONI, 2003, p. 105).

Os modelos não eram os preferidos dos lanternistas, o que limitava o objeto às coleções particulares dos nobres. 
Figura 9 - Imagem de lanterna mágica (a pessoa no balanço se move)

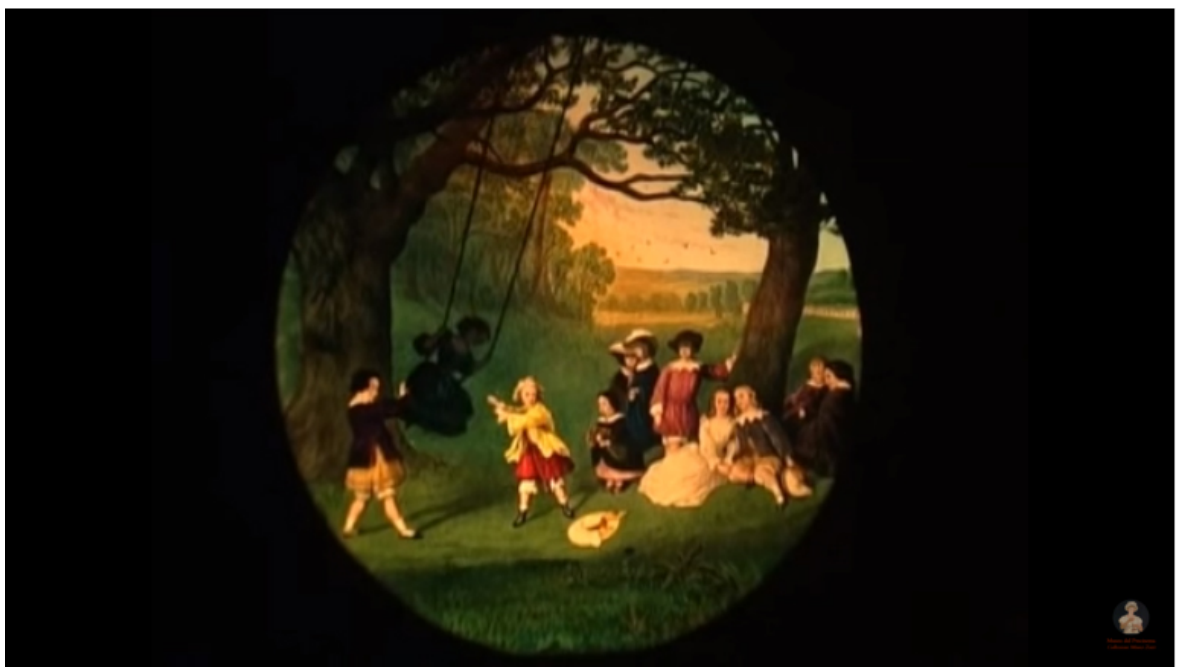

Fonte: Captura de tela de Rappresentazione con la Lanterna Magica (2009).

A divulgação dos espetáculos e projeções destacava o que eles traziam - imagens das cidades, animais estranhos, figuras diabólicas e assustadoras, etc. - e uma espécie de cientificidade como modo de atestar a importância da novidade (MANNONI, 2003). Ao mesmo tempo em que haviam os objetos direcionados ao entretenimento de várias pessoas; outros destinavam-se à fruição individual, como as caixas de perspectivas, armários que a cada abertura de porta apresentavam figuras diferentes (MANNONI, 2003). Entre a variedade imagética das projeções, algumas predominavam: "O demonismo foi durante muito tempo um dos temas prediletos da iconografia lanternista, mas curiosamente as placas abordando tal assunto proibido são hoje raríssimas, talvez porque fossem sistematicamente destruídas." (MANNONI, 2003, p. 126). A lanterna foi instrumento de êxito nos espetáculos de fantasmagoria no final do século XVIII, projeções de imagens estranhas e diabólicas que mais tarde seriam naturalizadas ao cinema:

Os espectadores jamais deviam ver o equipamento de projeção, que ficava escondido atrás da tela. Quando a luz da sala se apagava, um fantasma apareceria na tela, bem pequeno a princípio: aumentaria de tamanho rapidamente, e assim pareceria se mover em direção à plateia. Isso também podia ser feito no sentido inverso, com o fantasma distanciando-se e parecendo diminuir de tamanho. A retroprojeção tinha de ser sempre nítida: isso era possível graças ao tubo óptico aperfeiçoado da lanterna mágica, agora equipada com um diafragma, permitindo o ajuste da posição das lentes, e com uma cremalheira, que possibilitava o deslocamento da lanterna ao longo de trilhos ou sobre rodas. (MANNONI, 2003, p. 151). 
As pessoas até então não estavam acostumadas ao apelo dessas imagens. Além disso, era criado um "clima" para as projeções, como salas decoradas de forma estranha, com cortinas, o que acentuava o mal-estar do público (MANNONI, 2003). É interessante perceber que aqui já há uma preocupação em disfarçar o instrumento para que a ilusão se intensificasse e consequentemente ganhasse a atenção da plateia de maneira contundente. Conforme Crary (2012), "A fantasmagoria era o nome para um tipo específico de exibição da lanterna mágica na década de 1790 e nos primeiros anos do século XIX, que usava a retroprojeção para que o público não percebesse as lanternas." (CRARY, 2012, p. 130).

A partir do século XIX, principalmente pelas décadas de 1830 e 1840, muitos instrumentos ópticos intentavam justamente o contrário: a evidência dos sistemas mecânicos de funcionamento. Certos instrumentos que expunham a maquinaria criavam um efeito ilusório, alguns deles baseados na persistência retiniana, sendo um deles o fenacistoscópio, criado no começo da década de 1830 pelo cientista belga Joseph Plateau (CRARY, 2012).

\begin{abstract}
Ele consistia basicamente em um único disco, dividido em oito ou dezesseis segmentos iguais, cada um com uma pequena abertura, como uma fenda, e uma figura, representando uma posição em uma sequência de movimento. 0 lado com as figuras desenhadas era colocado em frente a um espelho, enquanto o espectador ficava imóvel à medida que o disco girava. (CRARY, 2012, p. 109).
\end{abstract}

Com esses mecanismos, as imagens pareciam estar em movimento diante do olho. Esse aparelho deu origem a outros parecidos, como o estroboscópio e o zootrópio. Crary (2012) salienta que essas máquinas não são cinema, embora seja pertinente observar como alguns objetos disfarçavam as estruturas de funcionamento; e outros as evidenciavam justamente como parte importante do espetáculo.

Com o desenvolvimento das pesquisas e experimentações técnicas, outros instrumentos foram aprimorados, sendo que essas transformações tentaram conhecer ainda mais as capacidades oculares. Entre eles estava o estereoscópio, difundido nos 1800: "No estereoscópio, duas imagens planas, desenhadas ou fotografadas, mas ligeiramente diferentes, eram justapostas verticalmente na caixa, em oposição a duas lentes." (MANNONI, 2003, p. 240). 0 instrumento proporcionava sensações mais realistas diante dos objetos:

O estereoscópio [...] proporcionou uma forma na qual a "nitidez" do efeito crescia com a aparente proximidade do objeto em relação ao espectador, e a impressão de solidez tridimensional tornava-se ainda maior na medida em que os eixos ópticos de cada um deles divergiam. 0 efeito desejado com 
o estereoscópio não era simplesmente a semelhança, mas a tangibilidade aparente, imediata. (CRARY, 2012, p. 120, grifo do autor).

De todo modo, a impressão de realidade era diversificada, dependendo do objeto usado e a representação evidenciada. Algumas imagens de estereoscópio tinham pouca tridimensionalidade ou profundidade de campo (MANNONI, 2003). O instrumento influenciou, inclusive, a pintura do século XIX e chegou a dar uma sensação de possessão da imagem (MANNONI, 2003).

A tangibilidade imagética do objeto fez com que ele obtivesse sucesso para a pornografia - um dos motivos da sua decadência, segundo Mannoni (2003). Outra razão foi que o realismo tátil poderia levar a um estranhamento, algo semelhante ao que ocorreu no surgimento do 3D (MANNONI, 2003).

Ver de maneira mais intensa e nítida corrobora a ideia de uma tentativa do homem em se aproximar do realismo da imagem. Se o sujeito é separado da representação, a ilusão de estar mais perto dela pode constituir-se uma alternativa na relação perceptiva. Contudo, conforme vimos nesses poucos exemplos expostos, nem sempre havia uma meta incessante pelo realismo, muito menos o objeto era consequentemente escondido. Em vários casos, o processo era parte da performance e a relação com a imagem flertava com o sonho, o estranho, o obscuro.

Não eram todos esses aparatos que tinham como objetivo a verossimilhança - eles eram variados, com funções diferenciadas e, muitas vezes, os estudos de cinema os colocam todos como instrumentos ópticos que levaram a uma forma visual evoluída no final do século XIX. Crary (2012) alerta para a necessidade de não se fazer generalizações:

Há uma ligação óbvia entre o cinema e essas máquinas da década de 1830, mas em geral trata-se de uma relação dialética de inversão e oposição, em que características desses aparelhos anteriores foram negadas ou ocultadas. (CRARY, 2012, p. 110).

Mesmo assim, as particularidades desses aparelhos não se extinguiram, uma vez que vários de seus preceitos influenciaram outros mecanismos audiovisuais nos últimos dois séculos.

Os instrumentos pré-cinema que não escamoteavam as estruturas operacionais nem sempre se adequaram aos anseios visuais com o passar do tempo, conforme salienta Crary (2012): 
Embora deem acesso ao "real", eles não têm a pretensão de que o real seja outra coisa a não ser uma produção mecânica. As experiências ópticas que fabricam são claramente separadas das imagens usadas no dispositivo. Tais experiências se referem tanto à interação funcional entre corpo e máquina quanto aos objetos externos, independentemente de quão "viva" seja a qualidade da ilusão. Nesse sentido, o desaparecimento do fenacistoscópio e do estereoscópio não foi parte de um simples processo de invenção e aperfeiçoamento tecnológico; essas formas mais antigas deixaram de ser adequadas às necessidades e aos usos da época. (CRARY, 2012, p. 129).

O uso desses aparelhos ficou pelo caminho em função do surgimento de outras propostas de visualidades. Essas transformações aconteceram dispersas e alteraram profundamente a atenção das pessoas, o que não ocorreu de modo gradual ou tranquilo. Crary (2013) já se refere aqui à situação do final do século XIX, quando cinema, telégrafo e outros impunham uma adaptação às transformações perceptivas de modo mais intenso e global. Em Suspensões da percepção, Crary (2013) coloca argumentos discordantes das ideias de nomes como Georg Simmel, Walter Benjamin, Siegfried Kracauer, Theodor Adorno, que caracterizaram a Modernidade por experiências de distração, como se antes houvesse uma atenção contemplativa estável. De acordo com Crary (2013):

[...] a distração moderna não é uma ruptura dos tipos estáveis ou 'naturais' de percepção contínua e imbuída de valores existentes durante séculos. A distração seria um efeito e, em muitos casos, um elemento constitutivo das diversas tentativas de produzir atenção em sujeitos humanos. (CRARY, 2013, p. 74).

Para Crary (2013), atenção e distração não formam polos opostos, mas podem ser pensadas como "[...] um continuum no qual as duas fluem incessantemente de uma para a outra, como parte de um campo social em que os mesmos imperativos e forças incitam ambas." (CRARY, 2013, p. 75, grifo do autor). Essa relação implica percebermos ainda que as mudanças em ambas começaram de forma gradual, passando por diversos mecanismos de subjetivação técnica e cultural.

As reflexões propostas acerca de alguns instrumentos visuais elencados corroboram as inferências do conceito de dispositivo de Foucault (1988) para se compreender a formação do olhar no cinema. Os aspectos discutidos que podemos enfatizar como exemplos desse processo são:

a) a câmara escura e o sujeito apartado da representação;

b) o observador de segunda ordem nas artes plásticas já como um efeito dos instrumentos de produção de imagem; 
c) os diversos artefatos visuais que estabeleceram modos de olhar a partir da exibição ou ocultação dos respectivos funcionamentos.

Outros elementos constitutivos do dispositivo do olhar poderiam ser citados, porém nos detivemos nesses. Relacionando essas ideias com a abordagem de Crary (2013) sobre as oscilações entre atenção e distração, cabe ressaltar que esses comportamentos não se aprofundaram apenas a partir dos instrumentos técnicos de produção de imagem. Eles já existiam antes, apenas se alteraram, e o que os três processos debatidos no presente texto mostram são certos movimentos dessas mudanças, como eles foram significativos para o cinema e revelam características fundamentais dos nossos hábitos de olhar.

\section{Considerações}

O balanço entre atenção e distração foi sendo alterado ao longo dos séculos em que novas experiências visuais foram engendradas por instrumentos técnicos diferenciados. Os estudos desses objetos é a investigação de como olhamos, da maneira como as imagens se apresentam a nossa percepção. No caso do audiovisual contemporâneo, marcado pela imagem de síntese, o realismo visual dessas obras pontua inquietações acerca da relação humana com a técnica que mantém conexões com formas antigas de registro. Ou seja, fundamentar a observação apenas a partir do suporte de gravação é desconectá-la do processo, das práticas que envolvem muitos outros aparelhos de produção de imagem, alguns deles descritos brevemente neste artigo.

Os modos de ver no Ocidente foram se desenvolvendo em uma rede de relações de poder, hábitos, discursos culturais, artísticos e sociais. Por isso autores como Foucault (1988, 1999) e Crary $(2012,2013)$ foram necessários para compreender tais processos de formação do olhar não apenas com o determinismo da técnica, pois essa também é atravessada por subjetividades, discursos, relações de poder. Da pintura da Renascença ao filme em 3D ou por webcam, câmera de vigilância e celular, muitos foram os artefatos responsáveis por moldar um certo tipo de olhar majoritário a partir dos hábitos visuais que se estabeleceram em função deles.

Através dos pontos abordados sobre a construção do olhar: a câmara escura e o sujeito apartado da representação; o observador de segunda ordem nas artes plásticas já como um efeito dos instrumentos de produção de imagem; e os diversos artefatos visuais que estabeleceram modos de olhar a partir da exibição ou ocultação dos respectivos funcionamentos pudemos perceber algumas transformações do dispositivo do olhar. Com a existência de algum processo maquínico para ver o mundo e objetos de formas variadas, a 
pintura se alterou. Quando a disseminação de múltiplos artefatos se expandiu, o esforço em se aproximar ao máximo dos objetos, ou criar a ilusão de, foi um rastro preponderante na criação do cinema.

Alguns desses instrumentos permaneceram e se desenvolveram para outros meios, já muitos desapareceram no tempo. Enquanto certos aparelhos disfarçavam o respectivo funcionamento; outros revelavam todo o engendramento das imagens. 0 processo foi descontínuo, errante, porém nos textos de arqueologia da mídia consultados, em especial Mannoni (2003), Zielinski (2006) e Crary (2012), a concepção de que há um predomínio pelo desejo de tangibilidade do mundo por meio da fruição com imagens se mostrou recorrente.

Ver mais, perceber detalhes pelo uso de algum instrumento, enxergar o que meu olho sozinho não consegue, essa questão aparece continuamente entre quem narra os processos históricos de formação do olhar. 0 sujeito apartado da representação desde os tempos da câmara escura busca meios de tentar subverter essa condição, mesmo que de maneira simulada. Relações de forças se travaram e levaram a homogeneizações (FOUCAULT, 1988), entre elas a da impressão, sensação de que o olhar mesmo descoporificado (CRARY, 2012) pudesse tornar tangível o mundo.

\section{Referências}

AGAMBEN, Giorgio. 0 que é um dispositivo? Outra travessia, n. 5, Florianópolis, segundo semestre de 2005. p. 9-16.

ATIVIDADE Paranormal 4. Direção: Ariel Schulman e Henry Joost. Produção: Jason Blum e Oren Peli. Intérpretes: Kathryn Newton, Matt Shively, Aiden Lovekamp, Katie Featherston et al. Roteiro: Christopher B. Landon e Chad Feehan. Los Angeles: Blumhouse Productions, 2012. 1 DVD (87 min), son., color.

BAUDRY, Jean-Louis. Cinema: efeitos ideológicos produzidos pelo aparelho de base. In: XAVIER, Ismail (org.). A experiência do cinema: antologia. Rio de Janeiro: Graal, 1983. p. 383-399.

BORDWELL, David. Sobre a história do estilo cinematográfico. Campinas: Ed. da Unicamp, 2013.

CHAUÍ, Marilena. Janela da alma, espelho do mundo. In: NOVAES, Adauto et al. 0 olhar. São Paulo: Companhia das Letras, 1988.

CRARY, Jonathan. Técnicas do observador: visão e modernidade no século XIX. Rio de Janeiro: Contraponto, 2012.

CRARY, Jonathan. Suspensões da percepção: atenção, espetáculo e cultura moderna. São Paulo: Cosac Naify, 2013. 
ESTEREOSCÓPIO. In: MICHAELIS: dicionário brasileiro da língua portuguesa. [S.l.]: Melhoramentos, 2018.

FENACISTOSCÓPIO. In: DICIONÁRIO Priberam. [S.l.]: Priberam Informática, 2018.

FOUCAULT, Michel. A história da sexualidade I: a vontade de saber. Rio de Janeiro: Graal, 1988.

FOUCAULT, Michel. As palavras e as coisas. São Paulo: Martins Fontes, 1999.

FRIEDRICH, Caspar David. Mulher diante da aurora. 1818a. 1 original de arte, óleo sobre tela, $44 \mathrm{~cm} \times 73 \mathrm{~cm}$.

FRIEDRICH, Caspar David. Penhascos de giz em Rügen. 1818b. 1 original de arte, óleo sobre tela, $90,5 \mathrm{~cm} \times 71 \mathrm{~cm}$.

GUMBRECHT, Hans Ulrich. Atmosfera, ambiência, Stimmung: sobre um potencial oculto da literatura. Rio de Janeiro: Contraponto, 2014.

KITTLER, Friedrich. Mídias ópticas. Rio de Janeiro: Contraponto, 2016.

MANNONI, Laurent. A grande arte da luz e da sombra: arqueologia do cinema. São Paulo: SENAC, 2003.

MARTINS, Simone. A Escola de Atenas, Rafael Sanzio. São Paulo, 2017. Reprodução do portal História das Artes da obra de Rafael Sanzio de 1511. Disponível em:

http://www.historiadasartes.com/sala-dos-professores/a-escola-de-atenas-rafael-sanzio/. Acesso em: 15 de jun. de 2019.

NASCIDO para matar. Direção: Stanley Kubrick. Produção: Stanley Kubrick. Intérpretes: Matthew Modine, Adam Baldwin, Vincent D’Onofrio, R. Lee Ermey et al. Roteiro: Stanley Kubrick e Michael Herr. Los Angeles: Warner Brothers, 1987. 1 DVD (116 min), son., color.

O ILUMINADO. Direção: Stanley Kubrick. Produção: Stanley Kubrick. Intérpretes: Jack Nicholson, Shelley Duvall, Danny Lloyd, Scatman Crothers et al. Roteiro: Stnaley Kubrick e Diane Jhonson. Los Angeles: Warner Brothers, 1980. 1 DVD (144 min), son., color.

RAPPRESENTAZIONE con la Lanterna Magica: Museo del Precinema di Padova. [S. l.: s. n.], 2009. 1 vídeo (3 min). Publicado pelo canal Museo del Precinema: Collezione Minici Zotti. Disponível em: https://www.youtube.com/watch?v=4D0-YuX-X80. Acesso em: 10 jun. 2019.

VELÁZQUEZ, Diego. As meninas. 1656. 1 original de arte, óleo sobre tela, 3,18 m x 2,76 m. Reprodução de Web Gallery of Art.

WEB GALLERY OF ART. [Database]. 2019. Disponível em: https://www.wga.hu/. Acesso em: 6 jul. 2019.

ZIELINSKI, Siegfried. Arqueologia da mídia: em busca do tempo remoto das técnicas do ver e do ouvir. São Paulo: Annablume, 2006.

ZOOTRÓPIO. In: DICIONÁRIO Priberam. [S.l.]: Priberam Informática, 2018. 


\title{
Notes about the formation of apparatus of seeing in the cinema
}

\begin{abstract}
This article brings some notes about the apparatus in the spectator's view formation in movies and discusses ways of see and feeling moving images. The apparatus of seeing its thought as a visual behavior organized in the narrative and the strategies of this to affect the way of seeing of the public, the respective speeches in attempting the sensitive appeal. Authors as Friedrich Kittler, Hans Ulrich Gumbrecht, Jonathan Crary, Marilena Chauí, Michel Foucault and Laurent Mannoni were the observation's base. The discussion begins with theoretical aspects around the concept and goes to the three processes of formation of the viewing and some visual instruments before the cinematograph. Such objects have left traces in the way as vision its composed in front of screens and the subjectivities derived from the human relation with these artifacts.
\end{abstract}

\section{Keywords}

Apparatus. View. Cinema. Technology. Image. Communication.

Recebido em 06/08/2018

Aceito em 25/04/2019 